J. Lake Sci. (湖泊科学), 2006, 18(5): $443-451$

http:// www. jlakes. org. E-mail: jlakes@ niglas. ac.cn

(c) 2006 by Journal of Lake Sciences

\title{
$1961-2003$ 年间鄱阳湖流域气候变化趋势及突变分析”
}

\author{
郭 华 ${ }^{1,2,3}$, 姜 榇 $^{1}$, 王国杰 ${ }^{1,2}$, 苏布达 ${ }^{1,2}$, 王艳君 ${ }^{1,2}$ \\ ( 1 : 中国科学院南京地理与湖泊研究所, 南京 210008) \\ (2:中国科学院研究生院, 北京 100039) \\ (3: 中国地震局地震预测研究所兰州科技创新基地, 兰州 730000)
}

\begin{abstract}
摘 要: 本文利用 $1961-2003$ 年间鄱阳湖流域 14 个气象站的气温、降水量、蒸发量等观测数据和 8 个主要水文站的流量 数据, 研究该时段内鄱阳湖流域的气候变化趋势、突变及其空间分布的差异. 研究表明, 鄱阳湖流域气温和降水均在 1990 年发生突变,继而呈现显著的上升趋势; 在季节变化上,冬季平均气温在 1986 年发生突变,增温显著;夏季降水量和夏季 暴雨频率均在 1992 年发生突变增加, 暴雨频率增加是夏季降水量增加的主要原因; 蒸发血蒸发量和参照蒸散量均呈现显 著下降趋势, 该变化在夏季尤为明显. 上述变化趋势均以 $1990 \mathrm{~s}$ 最为显著,这与长江流域气候变化趋势基本一致. 在空间 分布上, 饶河水系、信江水系和赣江下游等气候变化更为显著. 笔者认为, 鄱阳湖流域气候变化在长江流域中比较突出, 该流域 1990s 暖湿气候在加强; 气温的升高、降水量和暴雨频率的增加以及蒸发量的下降强化了五河流量的增加趋势, 由 此可大致判定鄱阳湖流域气候变化与洪涝灾害之间可能存在的关系,这可为理解气候变化在该流域的响应和预测该流域 未来可能的洪涝灾害提供依据.
\end{abstract}

关键词:鄱阳湖流域;气温;降水量;蒸发量;流量;气候变化;突变;空间分布;长江流域

\section{Observed trends and jumps of climate change over Lake Poyang Basin, China:1961 - 2003}

GUO Hua ${ }^{1,2,3}$, JIANG Tong ${ }^{1}$, WANG Guojie ${ }^{1,2}$, SU Buda ${ }^{1,2} \&$ WANG Yanjun ${ }^{1,2}$

(1: Nanjing Institute of Geography and Limnology, CAS, Nanjing 210008, P. R. China)

(2: Graduate School of the Chinese Academy of Sciences, Beijing 100039, P. R. China)

(3: Lanzhou Base of Institute of Earthquake Prediction, CEA, Lanzhou 730000, P. R. China)

\begin{abstract}
Based on observed data of 14 meteorological stations and six main hydrological stations in Lake Poyang basin, the trends and jumps of temperature, precipitation, pan evaporation (PE), reference evapotranspiration (ETr) and discharge are analyzed from 1961 to 2003. The results indicate that the temperature jumped in 1990, then it dominated an upward trend ever since 1990. Significant positive trend was noticed after 1986 in winter. As to precipitation, it changed abruptly in 1990. In 1992, the heavier rainstorm resulted in more precipitation in summer. Significant negative trend of PE and ETr was found, especially in summer. It was found that summer ETr fell sharply after 1992. As for spatial distribution, significant climate change areas are found in the Raohe River basin, the Xinjiang River basin and the lower reaches of the Ganjiang River basin. The climate change trends above-mentioned, that is coincident with the trend of the Yangtze River basin, are more obvious in 1990s. As a result, the runoff to the Lake Poyang also rose up. In 1990s, warm and humid climate tendency was strengthened. The climate change of Lake Poyang basin is much significant in the Yangtze River basin.
\end{abstract}

Keywords: The Lake Poyang basin; temprature; precipitation; pan evaporation; reference evapotranspiration; discharge; jumping changes; temporal and spatial trends; the Yangtze River Basin

* 水文水资源与水利工程科学国家重点实验室开放基金 (2004405511)、中国科学院南京地理与湖泊研究所知识创新 工程所长专项基金 (S240025) 联合资助. 2005-07-01 收稿: 2006-01-10 收修改稿. 郭华,女, 1977 年生, 博士研 究生,E-mail:qhguohua@163.com. 
鄱阳湖流域三面环山, 赣江、抚河、信江、饶河、修水由南、东、西向北注人鄱阳湖, 形成一个完整的流域 系统. 鄱阳湖是长江中下游通江湖泊, 对于调节长江中下游洪水具有举足轻重的作用. 鄱阳湖流域降水量 丰富, 时空分布不均, 其特有的气候变化特征、地理环境和人类活动等因素叠加导致洪涝灾害频繁. 历年洪 水统计表明, 该区域洪涝灾害和损失有越来越频繁、越来越大的趋势; 诸多研究认为, 这与长江流域中游地 区降水时空变化影响较大及人湖五大河流的来水有关 ${ }^{[1,2]} .20$ 世纪 90 年代与 50 年代相比, 洪涝灾害发生 的频率显著增加. 大的洪涝灾害在 90 年代就发生 3 次,即 1995 年、1996 年和 1998 年. $1948-1998$ 年的 51 年内, 年最高水位超过 $21.00 \mathrm{~m}$ 的共出现 5 次, 其中 3 次出现在 90 年代; $1988-1998$ 的 11 年间, 鄱阳湖最 高水位每年都在警戒水位 $19.00 \mathrm{~m}$ 以上; $1992-1998$ 年的 7 年内, 年最高水位超过 $20.00 \mathrm{~m}$ 的就有 5 年, 比 历史上任何时段都更为频繁 ${ }^{[1,3]}$.

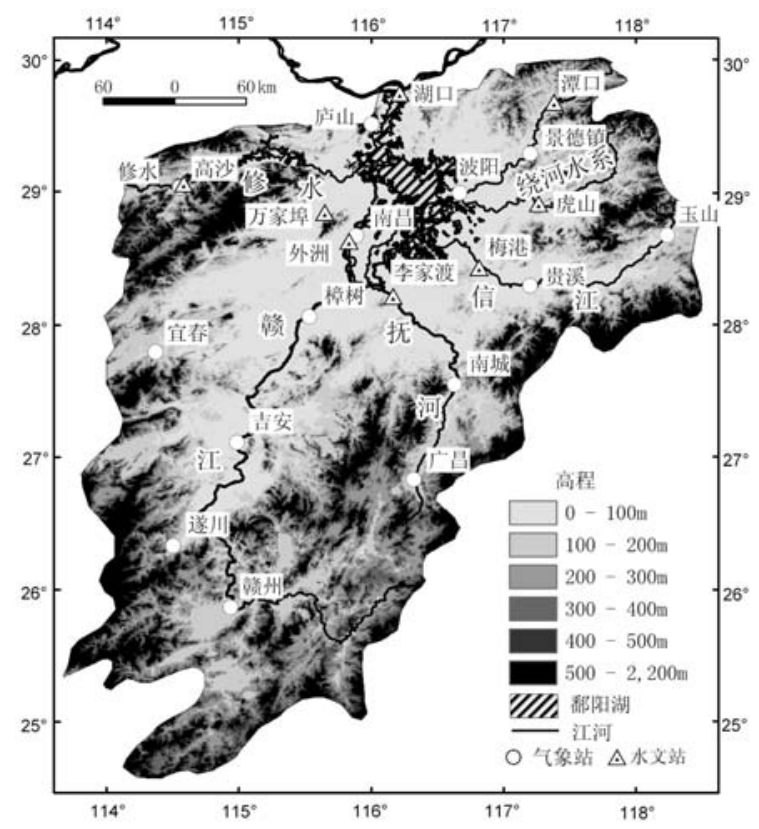

图 1 鄱阳湖流域水文气象站分布

Fig. 1 The location of the observatory stations in the Lake Poyang basin

1990s 洪水事件的增多除了与湖泊围圼造成 蓄洪功能减弱等因素有关外, 与全球变暖、水循环 加快引发的气候和水文过程变化的关系及其相关 程度 ${ }^{[4]}$ 如何, 对于这一问题的理解需要对长江中 游洪水频发的鄱阳湖流域的气候变化进行全面细 致的分析, 而气温、降水量、蒸发量及水文过程响应 是目前研究的重点. 本文利用 $1961-2003$ 年间鄱 阳湖流域 14 个气象站相关观测数据, 分析了该时 段内鄱阳湖流域的气候时空变化趋势. 该项研究, 对理解气候变化在本区域的响应和洪水频发与气 候变化的关系具有一定的参考价值, 同时对鄱阳湖 流域防洪治理具有十分重要的指导意义.

\section{1 数据和方法}

本研究选用的气温、降水量和蒸发量等数据由 中国气象局国家气象信息中心气候资料室提供 (1961.1.1 - 2003.12.31). 研究中采用计算 Von Neumann ratio( $\mathrm{N})$, Cumulative deviations $\left(Q / n^{-0.5}\right.$, $\left.R / n^{-0.5}\right)$, Bayesian procedures $(U, A)$ 统计量 ${ }^{[5,6]}$ 的方法, 对所选用气象站的实测数据(图 1 ) 进行均 一性检验 ( $95 \%$ 置信度).

暴雨计算选用日降水量数据 (中国气象局规 定, 日降水量 $>50 \mathrm{~mm}$ 为暴雨). 流域年平均温度为站点年平均温度的算术平均值, 年降水量为各月平均降 水量之和,夏季降水量为 6、7、8 月份降水量之和,参考距平时期为 $1961-1990$ 年. 蒸发量各项数据的算法 与降水量相同. 在进行各要素空间分布计算时, 采用目前应用较为广泛、插值精度较高的反距离权重插值 法 $(\mathrm{IDW}))^{[7]}$, 利用该法绘制空间分布图.

非参数检验更加适合于非正态分布数据, 本文的气象时间序列趋势分析采用 Mann-Kendall（以下简称 MK $)^{[8,9]}$ 检验和线性回归方法进行.

对于突变检测, 本文用奇异谱分析方法 (SSA, Singular Spectrum Analysis) ${ }^{[10,11]}$, 以 10a 为嵌人维数, 通 过重建序列趋势项消除数据噪音. 基于 CUSUM 统计量 ${ }^{[12]}$ 初步判定突变点产生的可能区间, 并根据均方差 (Mean Square Error) 最小原则判定显著性突变点,用“解靴” (bootstrap)算法进行显著性水平检验.

参照蒸散量 $(\mathrm{ETr})$ 由联合国粮农组织推荐使用的彭曼 - 蒙特斯公式 (Penman-Monteith) 计算 ${ }^{[13,14]}$ :

$$
E T_{r}=\frac{0.408 \Delta\left(R_{n}-G\right)+\gamma \frac{900}{T+273} \mu_{2}\left(e_{s}-e_{a}\right)}{\Delta+\gamma\left(1+0.34 \mu_{2}\right)}
$$

式中, $E T_{r}$ 为参照蒸散量 $(\mathrm{mm} / \mathrm{d}), \Delta$ 为饱和水汽压 - 温度曲线斜率 $\left(\mathrm{kPa} /{ }^{\circ} \mathrm{C}\right), \gamma$ 为干湿表常数 $\left(\mathrm{kPa} /{ }^{\circ} \mathrm{C}\right), R_{n}$ 
为地表净辐射 $\left(\mathrm{MJ} /\left(\mathrm{m}^{2} \cdot \mathrm{d}\right)\right), G$ 为土壤热通量 $\left(\mathrm{MJ} /\left(\mathrm{m}^{2} \cdot \mathrm{d}\right)\right), T$ 为 $2 \mathrm{~m}$ 高度的平均气温 $\left({ }^{\circ} \mathrm{C}\right), \mu_{2}$ 为 $2 \mathrm{~m}$ 高 度的风速 $(\mathrm{m} / \mathrm{s}), e_{s}$ 为饱和水汽压 $(\mathrm{kPa}), e_{a}$ 为实际水汽压 $(\mathrm{kPa})$.

水文站选取五河出口控制站及湖口站 (集水面积 $162225 \mathrm{~km}^{2}$ ). 五河控制站分别为: 赣江的外洲站(集 水面积 $80948 \mathrm{~km}^{2}$ ), 抚河的李家渡站(集水面积 $15811 \mathrm{~km}^{2}$ ), 信江的梅港站 (集水面积 $15535 \mathrm{~km}^{2}$ ), 饶河水 系的虎山站(集水面积 $6374 \mathrm{~km}^{2}$ )、潭口站(集水面积 $1760 \mathrm{~km}^{2}$ ) 以及修水水系的万家埠站(集水面积 3548 $\mathrm{km}^{2}$ ), 柘林水库人库站点高沙站 (集水面积 $5303 \mathrm{~km}^{2}$ ).

\section{2 气温变化趋势}

\section{1 年平均气温变化趋势}

对鄱阳湖流域 $1961-2003$ 年的年、季节气温序列 做趋势分析及突变检测, 自 1986 年气温开始呈现增加 趋势, 1990 年发生突变, 进人显著性增温时期 (表 1 ). $1990 \mathrm{~s}$ 平均温度比 $1961-1990$ 年的平均温度高出约 $0.27^{\circ} \mathrm{C}$, 而 1998 年增温幅度达到 40 年来的最大值 (图 2). 这一结果与姜泮等 ${ }^{[15]}$ 得出的长江流域 $1990 \mathrm{~s}$ 的平均温度比 $1961-1990$ 年的平均温度高出约 $0.3^{\circ} \mathrm{C}$ 非常接近. 而 $1991-2003$ 年的平均温度比 1961 -

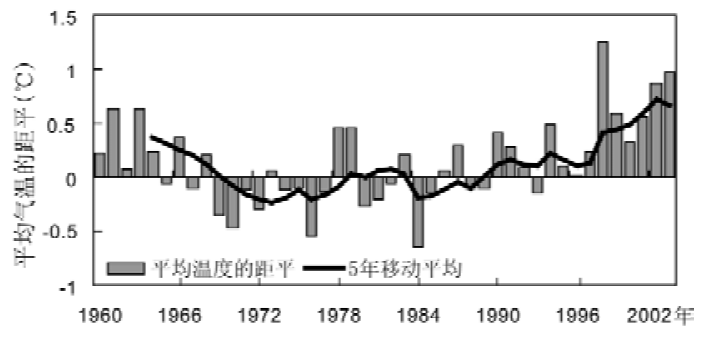

图 2 鄱阳湖流域年平均气温距平

Fig. 2 Annual mean temperature anomalies compared with mean value of 1961 - 1990, Lake Poyang basin 1990 年的平均温度高出约 $0.42^{\circ} \mathrm{C}, 1998-2003$ 年的平均温度则高出约 $0.75^{\circ} \mathrm{C}$.

鄱阳湖流域全年有 8 个月份的月平均温度具有增加趋势, 其中 6 月份和 12 月份的增加趋势较为显著; $3 、 7 、 8 、 9$ 月有下降趋势, 8 月份下降趋势非常显著. 就季节变化而言 (表 1), 鄱阳湖流域春夏秋三季平均温 度无明显趋势变化. 夏季平均气温有所下降但并不显著, $1990 \mathrm{~s}$ 夏季平均气温距平为 $-0.22^{\circ} \mathrm{C}$. 夏季平均 温度无明显趋势变化的原因是 6 月份具有显著增加趋势 ( $95.87 \%$ 的显著性水平), 而 8 月份下降趋势非常 显著 (99.54\% 的显著性水平). 冬季温度自 1986 年增温迅速而显著, $1991-2003$ 年冬季平均温度距平为 $1.02^{\circ} \mathrm{C}$. 用 $\mathrm{MK}$ 趋势检验方法检测出鄱阳湖流域气温变化趋势与整个长江流域基本一致.

表 1 鄱阳湖流域气温变化主要统计量

Tab. 1 Main statistics of temprature change in the Lake Poyang basin

\begin{tabular}{|c|c|c|c|c|c|c|c|}
\hline \multirow{2}{*}{ 时段 } & \multicolumn{2}{|c|}{ 平均温度 $\left({ }^{\circ} \mathrm{C}\right)$} & 重建趋势项主成 & \multirow{2}{*}{$\begin{array}{l}\text { MK } \\
\text { 统计量 }\end{array}$} & \multirow{2}{*}{$\begin{array}{c}\text { MK 检验显著 } \\
\text { 性水平 }(\%)\end{array}$} & \multirow{2}{*}{$\begin{array}{l}\text { 突变 } \\
\text { 年份 }\end{array}$} & \multirow{2}{*}{$\begin{array}{c}\text { 突变显著 } \\
\text { 性水平 }(\%)\end{array}$} \\
\hline & $1961-1990$ 年 & $1991-2003$ 年 & 分贡献率 $(\%)$ & & & & \\
\hline 春季 & 16.76 & 17.25 & 99.85 & 1.45 & 85.42 & - & - \\
\hline 夏季 & 27.35 & 27.25 & 99.96 & -0.07 & 5.83 & - & - \\
\hline 秋季 & 18.69 & 18.97 & 99.60 & 0.64 & 47.67 & - & - \\
\hline 冬季 & 6.48 & 7.50 & 98.17 & 6.25 & 99.99 & 1986 年 & 100 \\
\hline 年均 & 17.32 & 17.74 & 99.98 & 3.19 & 99.85 & 1990 年 & 100 \\
\hline
\end{tabular}

\section{2 气温变化趋势的空间分布}

鄱阳湖流域气温显著增加的地区主要集中在北部(图 3 ), 其中饶河流域气温增加趋势最为显著, 其次 为鄱阳湖区、信江流域中下游地区、抚河下游地区、赣江下游地区及修水中下游地区, 而赣江流域中上游地 区及抚河流域上游、修水上游变化并不明显.

\section{3 降水量变化趋势}

\section{1 降水时间变化趋势}

1961-1989 年平均降水量呈现振荡状态,并无明显趋势,但是在 1990 年发生突变后, 1990s 呈现明显 


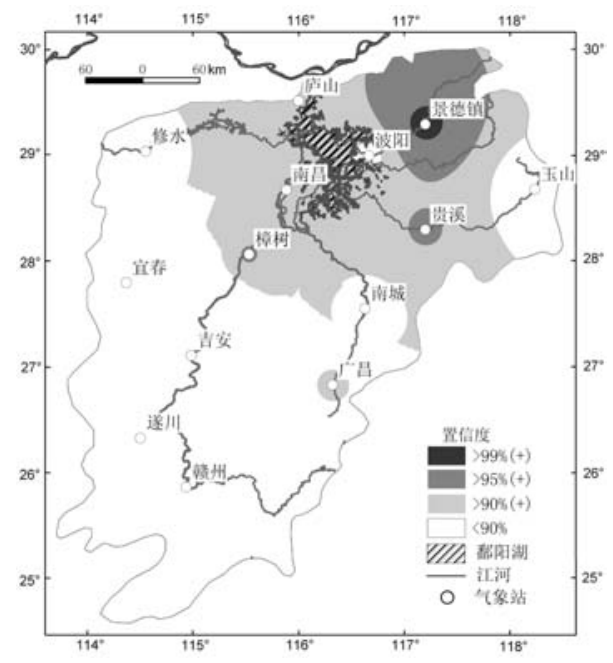

图 3 鄱阳湖流域年平均气温变化 MK 趋势的空间分布

Fig. 3 Interpolated Mann-Kendall trend of annual mean temperature
上升趋势(图 4).1991-2003 年平均降水量比 1961-1990 年平均降水量高出 $167.19 \mathrm{~mm}$. 夏季降水量和夏季暴雨频率 (图 5(a))均在 1992 年发生突变式的增加 (表 2), 然而夏季 暴雨强度 (图 5(b)) 以及夏季暴雨量占夏季降水量的比率并 没有显著变化. 这与长江流域同一时期降水趋势、暴雨频率 及暴雨强度 ${ }^{[15]}$ 的变化一致.

$1991-2003$ 年的夏季平均暴雨量、平均降水量分别比 $1961-1990$ 年的夏季平均暴雨量、平均降水量高出约 $107.81 \mathrm{~mm} 、 156.48 \mathrm{~mm}$, 可知该时期内夏季暴雨量距平占夏 季降水量距平的 $68.9 \%$. 1990s 平均暴雨日数比 $1961-1999$ 年平均暴雨日数多 $1.59 \mathrm{~d}$. 40 年间, 平均暴雨日数最高值出 现在 1999 年, 为 $9.07 \mathrm{~d}$; 而夏季暴雨频率最高是 1995 年和 1998 年, 分别为 $8 \mathrm{~d}$ 和 $8.36 \mathrm{~d}$. 就年内变化而言, 暴雨频率最 高的是 6 月份, 其中 1995 年和 1998 年 6 月暴雨最为频繁, 平 均发生次数分别为 $4.36 \mathrm{~d}$ 和 $3.57 \mathrm{~d}$; 暴雨频率增加最显著的 是 8 月, 通过了 $99 \%$ 的置信度检验. 可以认为, 夏季降水量 的增加主要是夏季暴雨频率增加的结果.

表 2 鄱阳湖流域降水变化主要统计量

Tab. 2 Main statistics of precipitation change in the Lake Poyang basin

\begin{tabular}{|c|c|c|c|c|c|c|c|}
\hline \multirow{2}{*}{ 主要指标 } & \multicolumn{2}{|c|}{ 面平均降水 } & \multirow{2}{*}{$\begin{array}{c}\text { 重建趋势项主成 } \\
\text { 分贡献率 }(\%)\end{array}$} & \multirow{2}{*}{$\begin{array}{c}\text { MK } \\
\text { 统计量 }\end{array}$} & \multirow{2}{*}{$\begin{array}{c}\text { MK 检验显著 } \\
\text { 性水平 }(\%)\end{array}$} & \multirow{2}{*}{$\begin{array}{l}\text { 突变 } \\
\text { 年份 }\end{array}$} & \multirow{2}{*}{$\begin{array}{c}\text { 突变显著 } \\
\text { 性水平 }(\%)\end{array}$} \\
\hline & $1961-1990$ 年 & $1991-2003$ 年 & & & & & \\
\hline $\begin{array}{l}\text { 年降水 } \\
(\mathrm{mm} / \mathrm{a})\end{array}$ & 1625.99 & 1793.18 & 98.04 & 4.05 & 99.99 & 1990 年 & 100 \\
\hline $\begin{array}{c}\text { 夏季降水 } \\
(\mathrm{mm})\end{array}$ & 527.78 & 684.26 & 99.42 & 1.96 & 94.96 & 1992 年 & 100 \\
\hline $\begin{array}{l}\text { 夏季暴雨 } \\
\text { 频率(d) }\end{array}$ & 2.44 & 3.69 & 99.50 & 2.46 & 98.61 & 1992 年 & 99 \\
\hline $\begin{array}{c}\text { 夏季暴雨 } \\
\text { 强度 }(\mathrm{mm} / \mathrm{d})\end{array}$ & 71.53 & 76.38 & 98.72 & 1.44 & 85.50 & - & - \\
\hline $\begin{array}{l}\text { 夏季暴雨量占夏季 } \\
\text { 降水的比率 }(\%)\end{array}$ & 37 & 42 & 99.17 & 0.65 & 48.45 & - & - \\
\hline
\end{tabular}

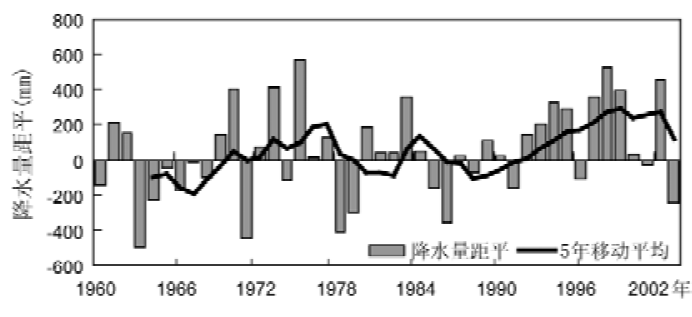

图 4 鄱阳湖流域年降水量距平

Fig. 4 Annual area-average preicipitation anomalies compared with mean value of $1961-1990$
根据以上分析,我们可以看到温度变化与降水量 变化有很好的对应关系: 降水量增加的季节, 温度下 降,特别是 7、8 两月这种关系更为明显; 1991-2003 年 平均气温增高, 降水量也在增加, 说明鄱阳湖流域暖湿 气候在加强.

\section{2 降水量变化趋势的空间分布}

对鄱阳湖流域 $1961-2000$ 年降水量的空间分布 规律进行分析后发现: 鄱阳湖流域近一半区域降水量 增加趋势明显,包括: 湖区、饶河流域、信江流域、修水 中下游地区、赣江中下游地区, 其中赣江中下游局部地 区增加趋势最为显著 (图 6). 除鄱阳湖北部少部分区 

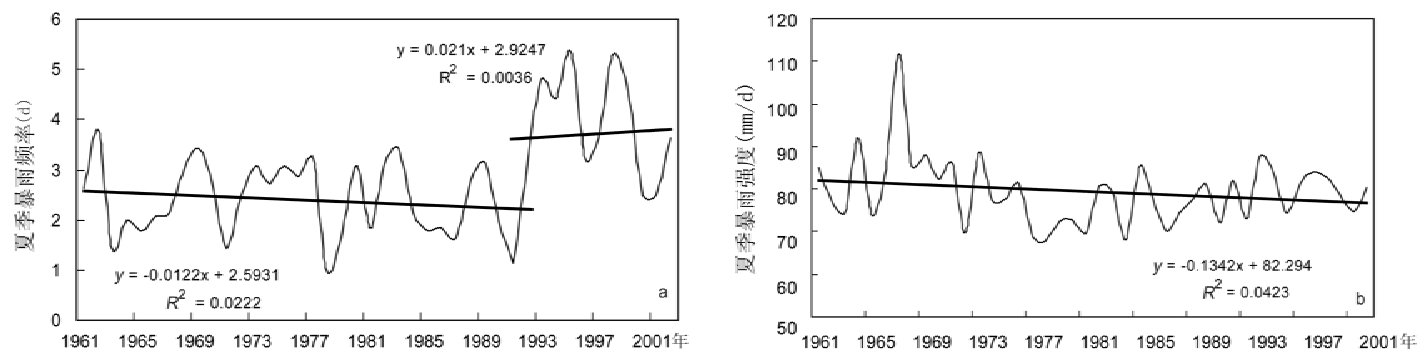

图 5 鄱阳湖流域夏季暴雨频率 $(\mathrm{a})$ 和暴雨强度 $(\mathrm{b})$ 变化趋势

Fig. 5 Summer rainstorm days(a) and rainstorm intensity (b) in Lake Poyang basin

域,湖区大部、饶河流域、信江中下游地区、赣江下游地区年降水距平都在 $250 \mathrm{~mm}$ 以上,修水流域、信江上游 地区年降水距平在 $200-250 \mathrm{~mm}$ 之间, 赣江中游地区及抚河的中下游地区年降水距平在 $100-200 \mathrm{~mm}$ 之 间,鄱阳湖流域的东南部,包括赣江上游和抚河上游地区年降水距平都在 $100 \mathrm{~mm}$ 以下. 而就 $1990 \mathrm{~s}$ 夏季平 均降水量相对于 $1961-1990$ 年夏季平均降水量距平的空间分布来看,湖区北部、饶河流域、信江流域降水 距平在 $250 \mathrm{~mm}$ 以上, 鄱阳湖区大部、赣江下游及修水中下游地区降水距平在 $200-250 \mathrm{~mm}$ 之间, 赣江中游、 修水中上游及抚河流域在 100-200 mm 之间, 只有赣江上游部分地区降水距平小于 $100 \mathrm{~mm}$ (图 7(a)). 由 以上可知,饶河流域和信江流域年增幅和夏季增幅都比较大.

1990s 鄱阳湖流域大部分地区的夏季暴雨日 数有所增加, 湖区北部、饶河流域、信江流域增加趋 势更为明显(图 7(b)), 这与夏季降水量距平空间 分布 (图 7(a)) 相似,说明暴雨是降水量增加的重 要贡献者.

\section{4 蒸发量变化趋势}

蒸发量是水量平衡的重要组成部分, 是了解气 候变化规律的重要因子. 由于资料等问题,目前计 算实际蒸发量比较困难. 蒸发血蒸发量虽不能直 接代表水面蒸发,但二者有很好的相关关系,而且 其时间序列长、可比性好 ${ }^{[16]}$, 所以我们采用 $20 \mathrm{~cm}$ 蒸发血蒸发量及由 Penman-Monteith 公式算出的参 照蒸散量来研究蒸发量变化趋势.

\section{1 蒸发血蒸发量和参照蒸散量时间变化趋势}

$1961-2000$ 年间鄱阳湖流域蒸发血蒸发量和 参照蒸散量均呈现下降趋势 (图 8 所示), 夏季尤 为显著. 1992 年之前的三十年夏季参照蒸散量相 对平稳, 无明显趋势变化, 1992 年发生突变, 蒸散 量显著下降(表 3). 1990s 夏季蒸发皿蒸发量、参 照蒸散量比 $1961-1990$ 年夏季平均蒸发量、平均 参照蒸散量减少 $76 \mathrm{~mm} 、 42 \mathrm{~mm}$. 秋季下降趋势明

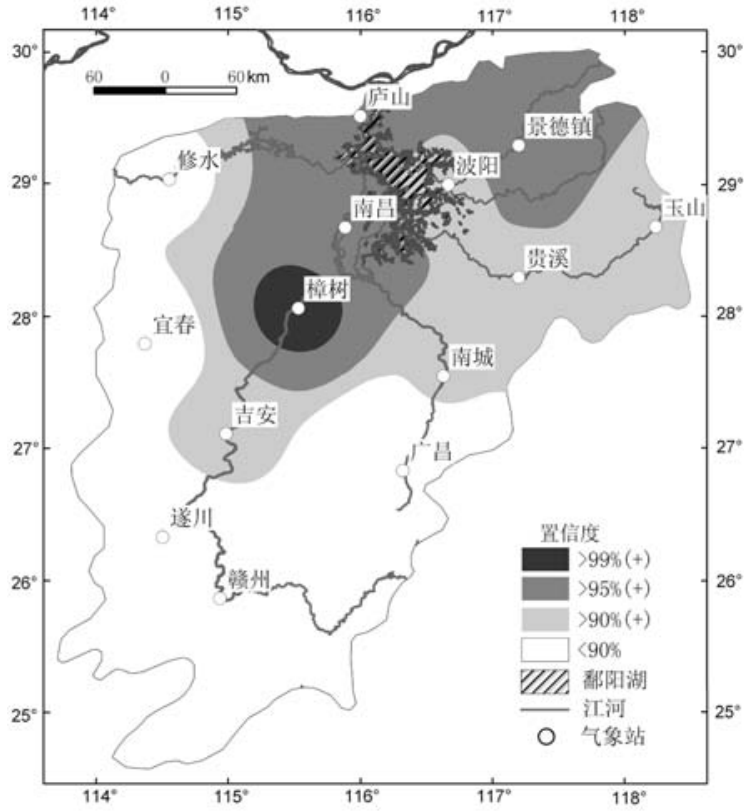

图 6 鄱阳湖流域降水变化 MK 趋势的空间分布

Fig. 6 Interpolated Mann-Kendall trend of annual mean precipitation 显,于 1981 年发生突变后趋于稳定 (表 3); 春季有较为稳定的下降趋势,并未检测到突变;冬季无显著的趋 势变化. 

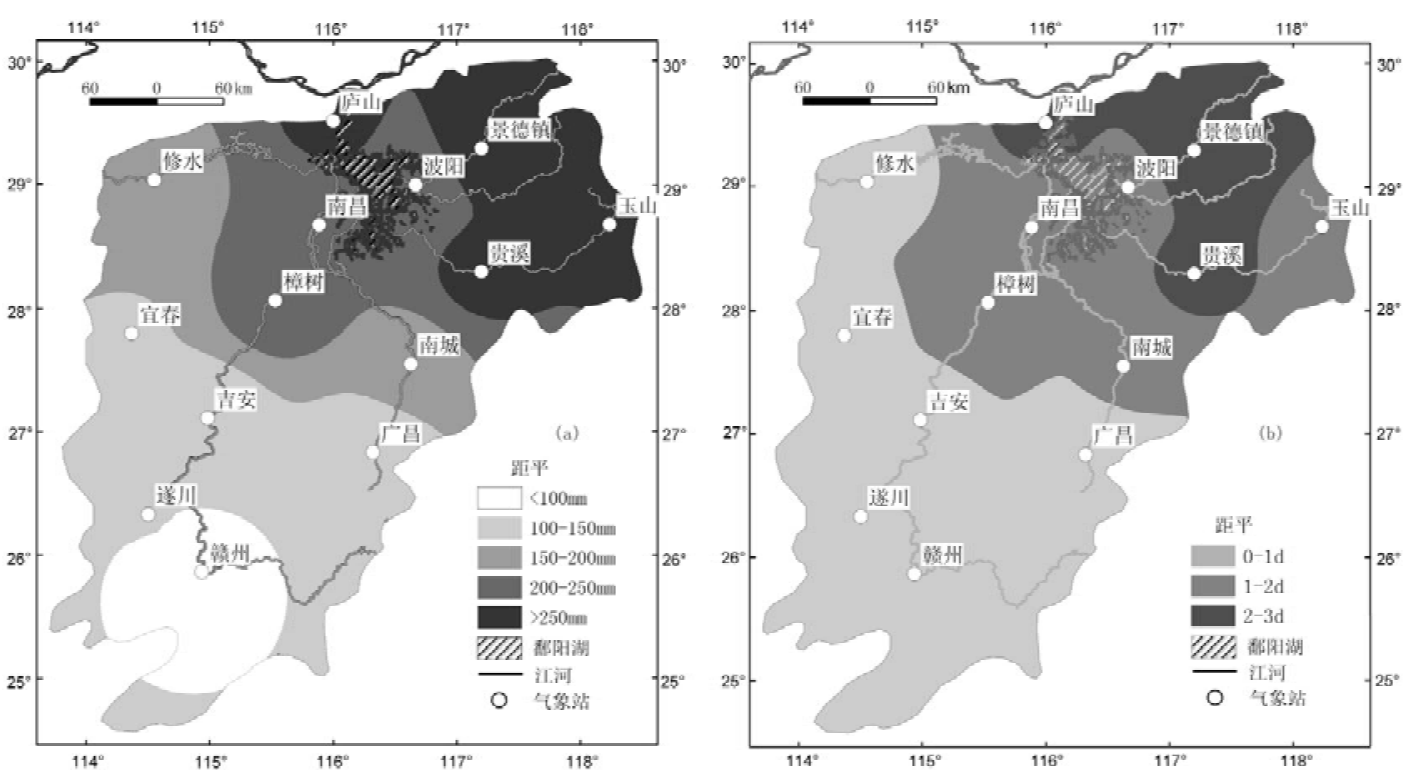

图 7 夏季平均降水量距平 (a) 和平均暴雨日数距平 $(b)$ 的空间分布

Fig. 7 Anomalies of summer precipitation(a) and rainstorm days(b) compared average value of 1991 - 2003 with mean value of 1961 - 1990

表 3 鄱阳湖流域参照蒸散量变化主要统计量

Tab. 3 Main statistics of ETr change in the Lake Poyang basin

\begin{tabular}{|c|c|c|c|c|c|c|c|}
\hline \multirow{2}{*}{ 时段 } & \multicolumn{2}{|c|}{ 平均蒸散量 $(\mathrm{mm})$} & \multirow{2}{*}{$\begin{array}{l}\text { 重建趋势项主成 } \\
\text { 分贡献率 }(\%)\end{array}$} & \multirow{2}{*}{$\begin{array}{l}\text { MK } \\
\text { 统计量 }\end{array}$} & \multirow{2}{*}{$\begin{array}{c}\text { MK 检验显著 } \\
\text { 性水平 }(\%)\end{array}$} & \multirow{2}{*}{$\begin{array}{l}\text { 突变 } \\
\text { 年份 }\end{array}$} & \multirow{2}{*}{$\begin{array}{c}\text { 突变显著 } \\
\text { 性水平 }(\%)\end{array}$} \\
\hline & $1961-1990$ 年 & $1991-2000$ 年 & & & & & \\
\hline 春季 & 263.94 & 259.66 & 99.50 & -1.77 & 92.34 & - & - \\
\hline 夏季 & 451.95 & 410.08 & 99.74 & -5.08 & 99.99 & 1992 年 & 100 \\
\hline 秋季 & 267.26 & 258.26 & 99.56 & -4.92 & 99.99 & 1981 年 & 100 \\
\hline 冬季 & 132.30 & 127.32 & 99.50 & -1.49 & 86.41 & - & - \\
\hline 年 & 1115.45 & 1055.32 & 99.94 & -4.73 & 99.99 & 1980 年 & 99 \\
\hline
\end{tabular}

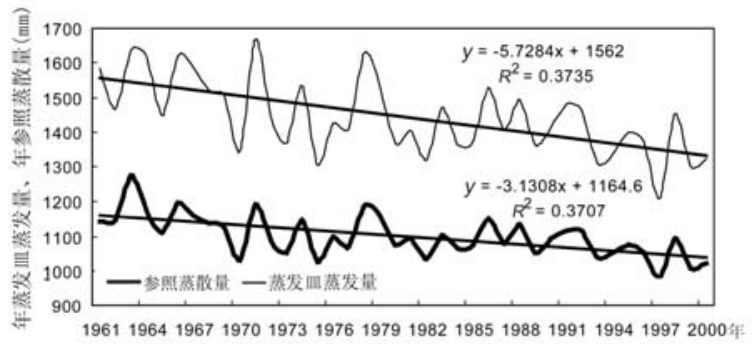

图 8 年蒸发血蒸发量 $(P E)$ 和参照蒸散量 $(E T r)$ 变化趋势

Fig. 8 Annual linear trend of $P E$ and Etr

综合全年来看,下降趋势较为显著. 就 年内变化而言,除 $6 、 12$ 月外,其他 10 个月份均呈 现下降趋势, 其中 $1 、 3 、 4 、 7 、 8 、 9$ 月份下降趋势显 著, 以 8 月份变化趋势最剧烈. 综合表 1 、表 2 及 表 3 可知,夏季蒸发量下降的显著性与温度的降 低以及降水量的显著增加有关.

\section{2 蒸发血蒸发量和参照蒸散量变化趋势的空间 分析}

根据鄱阳湖流域蒸发血蒸发量和参照蒸散 量变化的 MK 趋势检验, 除吉安和庐山很小部分 地区外,鄱阳湖流域 $90 \%$ 以上的地区蒸发血蒸发 量都呈显著减少的趋势, 除遂川地区外, 鄱阳湖流域参照蒸散量都显著减少,均通过了 $99 \%$ 的置信度检验.

1990s 夏季鄱阳湖流域北部地区,包括饶河流域、信江流域、修水中下游地区、赣江及抚河人湖地区蒸 发血蒸发量距平在 $-70 \mathrm{~mm}$ 以下,其中赣江人湖地区蒸发血蒸发量距平在 - $90 \mathrm{~mm}$ 以下; 赣江中上游地区、 
抚河中上游地区蒸发血蒸发量距平在 $-50 \mathrm{~mm}$ 至 $-70 \mathrm{~mm}$ 之 间 (图 9); 就参照蒸散量来说, 饶河流域、信江流域、修水中 下游地区、赣江中下游及抚河人湖地区距平在 $-40 \mathrm{~mm}$ 以 下,其中赣江下游部分地区、信江中下游部分地区距平在 ${ }^{29}$ $-50 \mathrm{~mm}$ 以下,而修水上游、赣江上游、抚河上游在 $-20 \mathrm{~mm}$ 至 $-40 \mathrm{~mm}$ 之间.

\section{5 流量对气候变化的响应}

根据五河水文控制站 $1961-2000$ 年平均流量数据分析 可知: 鄱阳湖流域五河水系各控制站都有不同程度的上升趋 势. 其中, 信江、饶河、修水水系的年平均流量的上升趋势最 26 为显著. $1990 \mathrm{~s}$ 赣江的外洲站、信江的梅港站和饶河的虎山 站的年平均流量分别比 $1961-1990$ 年平均流量高出 346 $\mathrm{m}^{3} / \mathrm{s} 、 112 \mathrm{~m}^{3} / \mathrm{s} 、 53 \mathrm{~m}^{3} / \mathrm{s}$ (表 4). 1990s 这三个控制站点的年 平均流量变化与其水系的气候要素变化有很好的对应关系; 饶河水系、信江水系和赣江下游平均气温显著增加 (图 3 )、 平均降水量显著增加 (图 6,7(a))、暴雨频率增加 (图 7(b)) 以及蒸发量显著下降(图9), 这些要素的变化趋势促成了流 Fig. 9 Spatial distribution of summer PE anomalies 量的增加趋势.

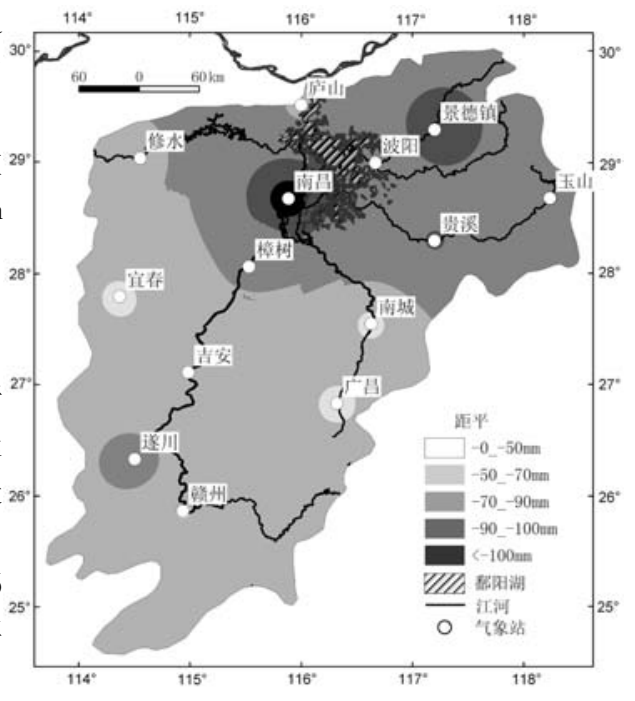

图 9 1990s 鄱阳湖流域夏季蒸发血蒸发量 距平的空间分布 compared 1991 - 2000 with $1961-1990$

表 4 鄱阳湖流域年平均流量的年代际距平 (单位: $\mathrm{m}^{3} / \mathrm{s}$ ) 及变化趋势的 $\mathrm{MK}$ 统计量

Tab. 4 Annual mean runoff anomalies in decadal scale (unit: $\mathrm{m}^{3} / \mathrm{s}$ )

and Mann-Kendall statistics on annual mean runoff trends in the Lake Poyang basin

\begin{tabular}{ccccccc}
\hline 站点 & 水系名 & $1960 \mathrm{~s}$ & $1970 \mathrm{~s}$ & $1980 \mathrm{~s}$ & $1990 \mathrm{~s}$ & MK 统计量 \\
\hline 外洲 & 赣江 & 32 & 66 & 9 & 346 & 1.17 \\
李家渡 & 抚河 & 2 & -8 & -23 & 29 & 0.42 \\
梅港 & 信江 & -40 & -29 & -43 & 112 & $1.72^{1)}$ \\
潭口 & 饶河(昌江) & -14 & -1 & 1 & 14 & $2.85^{2)}$ \\
虎山 & 饶河(乐安河) & -35 & 5 & -22 & 53 & $1.95^{1)}$ \\
高沙 & 修水 & -13 & -7 & -10 & 30 & $1.96^{1)}$ \\
万家埠 & 修水(潦水) & -18 & -3 & -6 & 27 & $2.8^{2)}$ \\
\hline
\end{tabular}

1) 表示通过 $95 \%$ 的置信度检验,2) 表示通过 $99 \%$ 的置信度检验.

鄱阳湖流域降雨季节性明显, 流量和洪峰流量存在较好的对应关系 ${ }^{[14]}$. 由于缺乏鄱阳湖出口控制 站一湖口站的 $1990 \mathrm{~s}$ 流量数据, 目前我们主要研究湖口站年最大洪峰流量趋势, 根据 $1961-2000$ 年湖口站 现有的年最大洪峰流量数据分析可知: 湖口站年平均流量分别比 $1961-1990$ 年平均流量高出 $7512 \mathrm{~m}^{3} / \mathrm{s}$; $1961-2000$ 年间, 年最大洪峰流量有明显增长的趋势, 通过了 $90 \%$ 的置信度检验.

\section{6 结论与讨论}

1) 综合 $1961-2003$ 年三个气候要素年和季节序列的趋势及突变特征, 发现年降水量和年气温均在 1990 年发生突变增加, 而夏季降水量 (增加) 和夏季参照蒸散量 (减少)在 1992 年发生突变, 说明: 1990s 鄱 阳湖流域气候的确发生了转折性变化. 年内变化以八月份最为显著. 由此可见,1990s 后,夏季气候变化对 年气候变化的贡献较大;1990s 鄱阳湖流域暖湿气候在加强. 值得注意的是, 冬季气温在 1986 年有一次增 加突变. 另外, 全年和秋季参照蒸散量还在 1980s 初出现了减少突变现象, 说明: 1980s 秋季和冬季的气候 变化对年气候变化贡献相对较大. 
2) 夏季暴雨频率和夏季降水量均在 1992 年发生突变增加, 暴雨频率最高的是六月份, 而暴雨频率增加 最显著的是八月份; 夏季温度的降低、降水量的显著增加, 增强了夏季蒸发量下降的显著性. 分析可知, 夏 季暴雨频率突变增加是夏季降水量突变增加的主要原因,继而导致年降水量突变增加.

3) 1990s 气温的升高、降水量和暴雨频率的增加, 以及蒸发量的下降加强了流量的增加趋势; 五河控制 站及湖口站的流量变化在一定程度上反映了流域气候变化的影响过程.

4) 在空间分布上,饶河流域、信江流域和赣江下游是 1961-2000 年间鄱阳湖流域气候变化最为显著的 地区;夏季,饶河流域和信江流域变化趋势最为显著.

5 ) 鄱阳湖流域气候变化趋势与长江流域气温 ${ }^{[15,20]}$ 、降水 ${ }^{[15,20-24]}$ 、暴雨 ${ }^{[15,20-25]}$ 、蒸发 ${ }^{[14,26]}$ 时间变化趋 势基本一致,在长江流域中比较突出.

上述气候变化趋势特征仅是 1961-2003 年间相关气象和水文数据的统计结果, 这些气候变化的物理 机制还待进一步探讨. 不过,1990s 以来长江流域的气候变化, 已经在温度 (升高)、降水量 (增加)、暴雨量 （增加）、蒸发量 (减少) 以及洪水事件增多上有所反映; 同时, 水文水资源系统已经或者正在发生变化, 加之 三峡工程的潜在影响,这些变化必然会对未来的生态环境产生影响. 若任这种影响持续发展,将可能对鄱 阳湖流域的水文水资源和生态系统等方面产生很大的负面影响甚至造成自然灾害,所以,应积极面对和提 出适应性对策, 以利于相关问题的解决.

致谢: 成文过程中得到中国科学院南京地理与湖泊研究所王洪道先生的悉心指导,特此表示衰心感谢.

\section{7 参考文献}

[1] 闵 骞. 20 世纪 90 年代鄱阳湖洪水特征的分析. 湖泊科学, 2002,14(4):323-330.

[2] 金腊华, 李明玉, 黄报远. 鄱阳湖洪灾特征与圩区还湖将来运用方式研究. 自然灾害学报, 2002,11 (4) :74-77.

[3] 朱宏富, 金 锋, 李荣昉主编. 鄱阳湖调蓄功能与防灾综合治理研究. 北京:气象出版社, 2002:20 - 22 .

[4] 施雅风, 姜 粀, 王 俊等. 全球变暖对长江洪水的可能影响及其前景预测. 湖泊科学, 2003,15(增 刊) $: 1-15$.

[5] Buishand T A. Some methods for testing the homogeneity of rainfall records. Journal of Hydrology, 1982, 58: $11-27$.

[6] Maniak U. Hydrologie und Wasserwirtschaft. Berlin: Springer(in German) ,1997.

[7] ArcInfo 中国技术咨询与培训中心 (姚永慧, 潘志强, 孙英君等编译). ArcGIS 地统计分析实用指南, $2002: 135-139$.

[8] Kendall M G. A new measure of rank correlation. Biometrika, 1938, 30: 81 - 93.

[9] Kendall M G. Rank Correlation Methods. London: Charles Griffin, 1975:1 - 202.

[10] 刘 禹, V. Shishov, 史江峰等. 内蒙古西部贺兰山和东部白音敖包未来 20 年降水趋势预测. 科学通 报, 2004,49(3):270-274.

[11] 段克勤,姚檀栋,蒲健辰. 喜马拉雅山中部过去约 300 年季风降水变化. 第四纪研究,2002, 22(3):236 -242 .

[12] Taylor Enterprises Inc. Change-Point Analyzer Software. (http://www. variation. com/cpa/index. html. )

[13] Allen R G, Pereira L S , Raes D, et al. Crop evapotranspiration-guidelines for computing crop water requirements-FAO Irrigation \& Drainage Paper No. 56. Rome:FAO, 1998:15 - 64 .

[14] 王艳君, 姜 䑣, 许崇育. 长江流域近 40 年蒸散 (发) 量变化趋势研究. 气候变化研究进展, 2005,1 (3) :99- 105 .

[15] 姜 形, 苏布达, 王艳君等. 四十年来长江流域气温、降水与径流变化趋势. 气候变化研究进展, $2005, \mathbf{1}(2): 65-68$.

[16] 邱新法, 刘昌明, 曾 燕. 黄河流域近 40 年蒸发血蒸发量的气候变化特征. 自然资源学报,2003,18 (4) :437 - 447. 
[17] 郭生练. 气候变化对洪水频率和洪峰流量的影响. 水科学进展, 1995,6(3):224-230.

[18］陈雄波, 唐洪武, 林 军. 赣江南昌段东西河分流处河床演变与航道整治. 人民长江, 2002,33 (4): $10-12$.

[19] 陈德亮, 高 歌. 气候变化对长江流域汉江和赣江径流的影响. 湖泊科学, 2003, 15 (增刊) : 105 -113 .

[20] Zhang Q, Jiang T, Gemmer M, et al. Precipitation, temperature and runoff analysis from 1950 to 2002 in the Yangtze basin, China. Hydrological Sciences Journal, 2005, 50(1): 65 - 80.

[21] 苏布达, 姜 粀, 施雅风等. 1990 长江流域降水趋势分析. 湖泊科学, 2003, 15 (增刊) : 38 - 48.

[22] Su B D, Jiang T, Shi Y F, Becker S, et al. Observed precipitation trends in the Yangtze River Basin from 1951 - 2002. Journal of Geographical Science, 2004,14(2) : 204 - 218.

[23] Becker S, Gemmer M, Jiang T. Observed and interpolated precipitation trends and variability in the Yangtze basin area. 湖泊科学, $2003, \mathbf{1 5}$ (增刊) : $123-129$.

[24] 李吉顺, 王昂生, 陈家田. 降水时空分布变化是长江流域水旱灾害加重的主要原因. 中国减灾, 1999, 9(4) :27 - 40 .

[25] 闵 骞. 鄱阳湖 1998 年洪水特征. 水文, 2001,21(3):55 - 58.

[26] Xu C Y, Gong L B, Jiang T, et al. Analysis of spatial distribution and temporal trend of reference erapotranspiration and pan eraporation in Changiang( Yangtze River) catchment. Journal of Hydrology, 2006 ( In Press, Arailable online 8 February,2006. )

\section{海洋与湖沼面临的全球性挑战—2006 年美国湖沼海洋学会夏季会议召开}

2006 年 6 月 4-9 日, 由有毒藻类国际研究协会、水生植物管理协会、美国渔业协会以及加拿大湖沼协 会共同协办的海洋与湖沼夏季会议在风景如画的加拿大维多利亚会议中心顺利召开. 大会的目的是提出并 讨论关于全球性水环境研究的最新进展. 来自欧洲、南美洲、亚洲、中东以及北美 1100 多位科学家出席了这 次会议. 大会邀请了近期的 10 位美国湖沼海洋学会 (ALSO) 奖获得者作各自相关研究领域最新进展的大会 报告, 其中包括著名湖沼学家 Brain Moss 教授(浅水湖泊,一个解决矛盾的方法)、David W. Schindler 教授 (运用科学说服公众政策,来自于试验湖泊的证据) 和 JoAnn M. Burkholder 教授(富营养化和有毒藻类暴发 之间的显著关系). 除此之外, 分会的口头发言和墙报在这次会议中也起到非常重要的作用. 这次会议的主 题是海洋与湖沼所面临的全球性挑战,会议主题按七个议题十个分会场同时进行交流,会议报告包括: (1) 全球气候变化对水生生态系统的影响, 尤其是二氧化碳及 UVR 的变化对水生生态系统物质循环、食物链结 构的影响, 以及生物本身对气候变化的适应. (2) 水生生态系统结构和功能的相互作用, 包括生态系统变化 的机制、生物多样性的作用、多态理论等. (3) 水生生态系统、陆地生态系统以及大气环境之间的相互作用 和水生生态系统之间的作用, 如湖泊、河流和海洋之间的相互作用, 能量流动以及物质迁移的机制, 以及物 质循环在生物化学过程在中的作用. (4) 保持健康水体所面临的压力, 如富营养化、水体缺氧、有毒藻类的 爆发、水体中的病原菌、水污染等压力. (5) 水资源的管理,包括全球或生态系统上的资源管理, 营养盐对生 态系统的响应. (6) 交流、教育,包括科学认识的普及程度、决策的依据、科学家作为建议者在政策制订中所 扮演的角色. (7) 海洋与湖沼未来所面临的问题, 如未来生态系统的压力, 水科学发展所需要的技术革新, 分子生物学在海洋与湖沼中的作用, 数据管理和网络建设以及模型方法的统一的重要性等. 除此之外, 会议 期间还举行了学生论坛. 总之, 会议为各国的科学工作者提供了相互交流和学习的机会, 并强调了有关研究 领域研究的亮点以及要重点加以解决的问题, 特别是关于海洋与湖沼研究领域最新的技术、方法等的探讨, 